\title{
Bottom-up initiatives and revival in the face of rural decline: Case studies from China and Sweden
}

\author{
Yuheng Li a , Hans Westlund ${ }^{\mathrm{b}}$, Xiaoyu Zheng ${ }^{\text {a, c, d, }}{ }^{\text {, Yansui Liu }}{ }^{\text {a, d, * }}$ \\ a Institute of Geographic Sciences and Natural Resources Research, Chinese Academy of Sciences, Beijing, 100101, China \\ ${ }^{\mathrm{b}}$ Department of Urban Planning and Environment, School of Architecture and Built Environment, KTH Royal Institute of Technology, Sweden \\ ${ }^{\mathrm{c}}$ University of Chinese Academy of Sciences, China \\ d College of Resources Science \& Technology, Beijing Normal University, China
}

\section{A R T I C L E I N F O}

\section{Article history:}

Received 30 October 2015

Received in revised form

1 July 2016

Accepted 4 July 2016

Available online 18 July 2016

\section{Keywords:}

Population loss

Rural decline

Rural revival

Bottom-up initiatives

Social capital

Sustainability

\begin{abstract}
A B S T R A C T
It is necessary for rural communities to meet conditions of decline, including depopulation, with effective strategies for rural revival and revitalisation. Based on Hirschman's 'exit-voice' theory, this paper investigates the way in which local stakeholders respond to processes of rural depopulation. Case studies undertaken in Xiaoguan village in China and in Åre in Sweden reveal the effectiveness of bottomup revitalization initiatives in combating rural decline. We show how local stakeholders' strong "voices" in these places-which called for improved living conditions and increased job opportunities-held people and groups together, encouraging them to work together with shared values and attitude. The strong leadership demonstrated either by local committees or in stakeholders' self-organized actions played an important role in carrying out revitalisation initiatives. We highlight the importance of not only reviving economies but also creating desirable rural lifestyles. Our findings also emphasize the need for bottom-up initiatives to align with government policy and regional development plans.
\end{abstract}

(C) 2016 Elsevier Ltd. All rights reserved.

\section{Introduction}

The twentieth century constitutes a period of massive change- from the introduction of automobile to commercial air travel to the development of computer technologies, we have seen technology bring about shifts which have dramatically influenced the course of human life. Few changes have been as significant as the dramatic shift of population from rural to urban areas globally (Wood, 2008). To give some idea of the scope of this movement, we only have to look to the United States: whilst most Americans lived in rural communities in 1900 , by the turn of the present century more than $80 \%$ of the population lived in urban areas. Similar trends can be seen in the countries of Europe since 1900, with rural depopulation accelerating in recent decades. According to the United Nations, the rural population of Europe fell from 207.3 million in 1985 to 192.8 million in 1995 , and is projected to fall to 128.4 million by $2025 .^{1}$ The rural decline which accompanies these

\footnotetext{
* Corresponding author. Institute of Geographic Sciences and Natural Resources Research, Chinese Academy of Sciences, Beijing, 100101, China.

E-mail address: liuys@igsnrr.ac.cn (Y. Liu).

1 United Nations Human Settlements Programme, Tools and Statistics Unit: Europe, http://ww2.unhabitat.org/habrdd/trends/europe.html.
}

processes of rural depopulation and urbanization can be seen in a drastic reduction in the quantity and quality of services available to rural citizens, an aging population, an articulated desire amongst young people to permanently leave rural areas, and the concomitant closure of schools in rural areas.

Unlike the countries of the developed world-countries like the US and Sweden, where urbanization often takes place at the expense of cities at lower levels in the urban hierarchy (Bontje, 2004; Schilling and Logan, 2008)—in the developing world, urbanization still takes place predominantly at the expense of the countryside (Westlund, 2014). As a result, the "hollowing out" of the countryside has become a widespread concern in many developing countries (Carr and Kefalas, 2009). The world's largest nation, China, has seen a mass migration of peasants to cities and an urbanization rate that has increased from $10.6 \%$ in 1949 to $52.6 \%$ in 2012; this development has induced challenges such as labour shortages, industrial recessions, a lack of infrastructure, loss of cultural heritage, and social conflicts (Liu et al., 2010; Sun et al., 2011; Long et al., 2011, 2012). The once self-sufficient villages have become hollowed out by these developments and many areas of rural China now exist in a state of decay.

"Counterurbanization", a "rural renaissance" was noted in many developed economies in the 1970s (Beale, 1975; Berry, 1976; 
Champion, 1988) and the trend has been visible also thereafter in certain periods and areas. Countries that experienced this trend include the US (Nelson et al., 2010), the UK (Phillips et al., 2008), Australia (Gibson et al., 2005), New Zealand (Freeman and Cheyne, 2008), Sweden (Borgegård et al., 1995; Westlund, 2002) and Spain (Solana-Solana, 2010). Through this process, wealthy urban residents who were driven by a desire to escape the city and to connect to an idealised rural space became a key source of rural population growth (Nelson and Nelson, 2010).

Compared to the post-industrial countries of the developed world, China is currently undergoing rapid industrialization and urbanization, and Chinese cities still constitute the core areas for the agglomeration of resources like labour, capital, material and information (Li, 2012; Li and Zhang, 2013). Although the suburbanization witnessed in China in the late 1990s somewhat slowed the pace of rural depopulation (Zhou and Ma, 2000), this slowing predominantly reflected a form of urban expansion which urbanized suburban villages. Middle and upper-class urban residents who relocated to the suburbs were able to retain their jobs, and their business and social connections, whilst making use of better services and infrastructure than those available in the countryside (Li, 2011). Given these dynamics, rural decline is most pertinent in relation to smaller rural communities that are far away from urban areas. No real "rural renaissance" or "counterurbanization" has been seen in China to date.

Migration from the countryside to cities is a natural component of urbanization and industrialization. These processes bring economic benefits but also induce a range of social and environmental problems if the increased population mobility that drives them is achieved through a trade-off with increasing urban-rural inequality. For the world's largest country, the depopulation of rural areas has not only lead to severe social problems but also increasingly represents a threat to food security. Whilst other countries might solve issues of shortage through increasing their reliance on imports, China is prevented from such action due to the massive increase in global food prices such a strategy would produce, a situation which would be accompanied by a range of unforeseen consequences, especially for poor countries. The situation in Sweden is totally different, where agriculture is a marginal activity in large parts of the country. The depopulation of the Swedish countryside is mainly a social and cultural problem caused by weak labour markets. Besides alleviating these problems, rural revitalization in Sweden would mean pursuing a more efficient use of rural labour and other resources.

Diverse policies and measures have been introduced in countries across the world in order to try to meet the challenges presented by rural decline, including attempts to stimulate the rural economy by improving local infrastructures and restructuring dispersed settlement patterns (van der Ploeg et al., 2000; Cullingworth and Nadin, 2002; Hassebrook, 2003; Bjorna and Aarsaether, 2009; Natsuda et al., 2012). The risk faced in these top-down policy, planning and investment initiatives is, however, that they may fail to conform to the real needs of local populations. Learning from such failures, local governments in rural areas facing depopulation increasingly call upon the collective self-reliance of people to shape and maintain their own living environments (Elshof and Bailey, 2015). As Richard E. Wood (2008, pp. xvii) highlights in his book Survival of Rural America, "Broad public policy and planning initiatives are interesting and, in some cases, necessary, but in the end the success of most communities individually, and of rural America as a whole, will depend more on the actions and commitment of the people who live there."

This paper investigates the role played by bottom-up initiatives in revitalising rural areas in response to conditions of rural decline. The second section of the paper reviews the reasons why rural decline takes place and the forces that drive rural revival. In the third section, we analyse the role played by local stakeholders in rural revitalization, through two case studies: one in China and one in Sweden. The fourth section discusses the importance of bottomup initiatives in rural revival and explores how such initiative can be made to work successfully.

\section{Theoretical interpretation of rural decline and rural revival}

\subsection{The exit-voice dichotomy}

Rural decline and possible rural revival are results of intertwined actions undertaken by individuals, private organizations (primarily companies) and political organizations. This study takes its point of departure from the proposition that urbanization is driven by differences in living standards between places-differences which themselves originate from differences in productivity between rural agriculture and urban industry and services. Private companies exploit these productivity differences by establishing and expanding their operations in cities. Politicians at various levels in turn support such development by creating favourable conditions for urban business growth. Such a pattern is then reinforced by the theory of circular and cumulative causation and the notions of the "centre" and "periphery" first propounded by regional development theorists such as Gunnar Myrdal (1957) and John Friedmann (1966). ${ }^{2}$ According to this view, the growth of large urban centres contributes to the decline of small rural centres in a cumulative manner.

Individuals make the decision to move from the countryside to cities based on their consideration of information about labour markets and salaries, but also by virtue of other "soft" factors such as culture, career opportunities, social reasons, etc. In Hirschman's (1970) terms, based on this information, individuals make their choice to "exit" (to leave). For Hirschman, the notion of exit is framed within a dichotomy which sets it against the notion of "voice"-a term that stands for the alternative choice to (rather than leave) stay and take action to improve a situation. Hirschman's seemingly simple dichotomy can be, and has been, applied to virtually all areas of society: e.g., consumer behaviour, social relations, labour markets, associational membership, housing and migration. In this paper, we focus on the decision to migrate ("exit") or stay and take action ("voice").

While "exit" in this context denotes the act of leaving a rural community, the use of "voice" can take several forms. One form would be to initiate a new business activity as a complement to or replacement for existing agricultural activities, either as an individual or together with others. Another form would be to take political action with the aim of achieving politically sanctioned investments (for instance, in infrastructure or industry) in the rural area in question, and in this way kick-start or enhance processes that result in improved living standards. ${ }^{3}$ The extent to which such investments will be made depends on the strength of political pressure from below and on how these claims are received by political decision makers at higher levels.

What determines whether an individual chooses to exit or to use voice? Assuming that individuals' decisions are based on some

\footnotetext{
${ }^{2}$ Later on, these processes have been given more formalized, theoretical explanations by the New Economic Geography, e.g. in Krugman (1991) and Venables (1996).

3 "Voice" in public policy concerns of course not only the issues of depopulation that we focus on in this paper. For example, an application and development of the voice concept is Senecah's "practical theory of the trinity of voice" that treats "... multistakeholder, multiobjective needs in complex environmental public policy processes" (Senecah, 2004, p. 22).
} 
kind of rationality, the individual bases his or her choice on an (often implicit) estimation of the costs and the benefits of staying versus the costs and the benefits of leaving. The higher the positive difference in estimated net benefits for leaving compared with the net benefits for staying, the greater the number of individuals that will choose to exit. However, the costs and benefits of the two alternatives are influenced by a large number of factors. One important factor is to what extent the exercise of "voice" is even possible. This is determined by both individual and structural conditions. Individuals with access to economic, human and/or social capital normally have a greater possibility of using "voice" compared with individuals who have no or low access to these resources. As expressed by Senecah (2004), voice is dependent on access (to information and to expressing ones opinions) and standing (respect, courtesy, etc.) that in combination leads to influence. Structural conditions in a society such as the degree of democracy, power relations, mechanisms of resource allocation, access to education, etc., generally strongly impact on the possibility to use "voice". Taken together, these personal and structural factors together constitute the general determinants of an individual's use of voice for the purposes of achieving rural revival.

\subsection{The driving forces of rural revival}

During the urbanization process, peasants generally move to cities, a shift which inevitably induces conditions of rural decline. Despite this general pattern, however, a diverse range of factors are involved in revitalization efforts seeking to combat rural decline. Firstly, we note the importance of the process of "rural gentrification", a term which has been increasingly used and applied in advanced post-industrial countries like the US and Spain in order to describe the transformation of rural communities by the migration of middle- and upper-class urban households to rural areas in reaction to their dissatisfaction with suburban living and their pursuit of a perceived higher quality of life available in the countryside (Nelson et al., 2010). The key features of this process include: increasing residential mobility, a preference for a "country lifestyle", and the involvement of highly educated, qualified and affluent (that is, middle-class) migrants (Stockdale, 2010). Globalization, which has tended to benefit wealthy urban professionals, is widely recognized as having enabled these actors to relocate to high-amenity destinations and is thus highlighted as a key driver of rural gentrification (Nelson, 2005).

The rural restructuring of post-productive villages (Bowler et al., 1992; Marsden and Sonnino, 2008) has also established a platform for rural immigration and gentrification in a number of ways. Firstly, the amalgamation of farms and the substitution of machines for labourers have made the purchase of these properties possible for people moving from cities (Spencer, 1997). Secondly, economic restructuring has rendered rural economies much more similar in structure to their urban counterparts. Taking the US as an example, we note that the decline of the share of employment provided by the primary and secondary sectors in the period 1970-2000 was accompanied by significant increases in the tertiary sector, which provided $61.8 \%$ of the total employment (Vias and Nelson, 2006). As a result, the expanding rural service sector has attracted many new inhabitants who have been drawn to low-wage employment opportunities in the countryside (Naples, 2000; Torres et al., 2006; Nelson, 2007).

Local, regional and national planning policies have reduced many perceived disadvantages to living in a rural locality, a third factor that must be taken into account in building a nuanced image of the process of rural revitalization. In practical terms, improved communication and transportation technologies have made rural areas much less isolated than they were only a few decades ago.
Satellite technology and the internet (along with the faxes and phones that preceded email) are among the most familiar aids, rendering distance virtually irrelevant in the transmission of information (Johnson and Beale, 1998). These changes radically increased the possibility for individuals to realise their preferences for a rural life (Stockdale et al., 2000).

\section{Case studies from China and Sweden}

Hirschman's exit-voice dichotomy has often been used as a background for migration studies and intuitively it seems easy to apply it in relation to the phenomenon of rural depopulation and the attempts that have been made to prevent rural decline. However, the potential to use "voice" and the forms that "voice" can take are, as suggested in the preceding discussion, highly contextdependent. To investigate the diverse forms of "voice" possible, we have selected two case study villages, one in a country characterised by an advanced economy, Sweden, and one located in a country with a developing economy, China. Whilst both Sweden and China are characterized by rural depopulation outside of the zones of influence surrounding expanding cities, the two selected villages go against this general trend and have succeeded in revitalizing their local economies. They have, however, done this in different ways: in the Swedish case by developing tourism, in the Chinese case by developing agriculture.

\subsection{Bottom-up initiatives in China's rural revival}

Rural China has experienced drastic transformations in recent decades (Long et al., 2011; Su et al., 2011). The country has witnessed the collapse of once flourishing township and village enterprises in the 1990s in response to economic restructuring. As a result of the urban bias that has for many decades characterised policy trajectories, rural areas severely lag behind cities in terms of income, infrastructure, social security and services like medical care and education. Both "push" and "pull" factors have subsequently driven large numbers of rural labourers to migrate to cities in order to chase their dreams of finding fortune. Although the Chinese government initiated a complete shift away from an urbanbiased policy platform to one that comprehensively supports agriculture, villages and peasants at the beginning of the twentyfirst century (Li et al., 2010; Li and Hu, 2015), the trend towards large-scale rural-urban migration has not been reversed and rural development capacity continues to be impaired due to the population losses being suffered.

Xiaoguan village should be the epitome of a depopulated rural village in China, however it has survived the onset of rural decline as the result of bottom-up initiatives led by its village committee, in which all village members are involved. ${ }^{4}$ Xiaoguan village is located in Yangyuan, a county that is ranked as "poor" in national categorisations and that is located in Zhangjiakou city, Hebei Province (Fig. 1). Among the 188 rural households that make up the Xiaoguan community, 117 households are considered "poor", earning an annual average per capita income that is below the national poverty line of 2300 Yuan (\$376). Challenged by water shortages and low productivity due to saline land and a weak economy, Xiaoguan village, like many other villages of Yangyuan County, has experienced significant depopulation. In fact, 120 young adults of

\footnotetext{
${ }^{4}$ This material was collected by interviews and questionnaires conducted by the authors in Xiaoguan village during the Third Party Appraisal of China's Targeted Poverty Alleviation in June 2015. The appraisal was carried out by the Institute of Geographical Sciences and Natural Resources Research at the Chinese Academy of Sciences.
} 


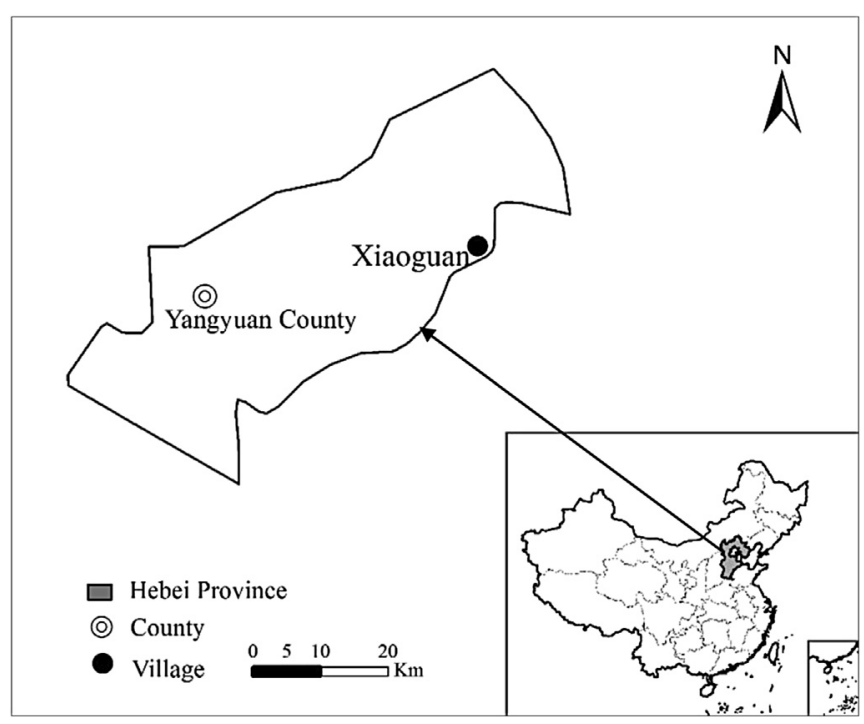

Fig. 1. Xiaoguan village in Yangyuan County, China.

the total 547 villagers - a number which is around half of the village's labourers-chose to "exit" and migrated to cities to work in 2011. This move severely impaired the endogenous development capacity of the village.

In 2012, driven by the ambition of "poverty alleviation and becoming rich", the village cadres of Xiaoguan decided to develop a collective economy integrating all the households that make up their rural community. A share-based cooperative system for mutton sheep breeding was subsequently established in Xiaoguan, wherein each share cost 5000 Yuan and each household was supported in purchasing one share through a subsidy granted by the village committee. In order to account for income differences and the affordability of the shares for peasants, the most impoverished households were able to purchase their share at a fully subsidized rate; poor households received 4000 Yuan in subsidies, while the subsidies for ordinary households were 2000 Yuan. Wealthy households bought into the system at 5000 Yuan per share, without any subsidies. Besides these private share purchases, the village committee also holds a number of shares collectively, contributing collective-owned land also investing national funds in the scheme. As a result, over 4.1 million Yuan was mobilised and used for sheep breeding, mutton processing and sales. Following the same method, 209 vegetable greenhouses were constructed in the fall of 2013; the village households acted as shareholders in this scheme too. Once the vegetables in each of the greenhouses were sold, 400 Yuan was allocated for infrastructure construction and social public welfare in Xiaoguan village.

A range of benefits can be seen in Xiaoguan village as a result of this programme. First, the two cooperatives, which are managed by the village committee, work to bind together the interests of all the households of Xiaoguan village. Guided by the committee, capital, labourers, land and other production elements are mobilised for collective production. This contributes greatly to the enhancement of Xiaoguan's development capacity. Second, as shareholders of the cooperative's shares, each household can choose to work either in the cooperative or to work in cities. At present, over 90 villagers are employed in the sheep breeding and greenhouses management activities. With particular relevance to the themes explored in this paper, we note that 60 migrant workers have returned to Xiaoguan and joined the local industries in the period following the initiation of the programme. The diversified income sources and returns on shares have brought about a sharp increase in households' incomes in Xiaoguan village. In 2014, the peasants' per capita net income reached 8100 Yuan; it was only 2000 Yuan in 2011. The rural collective's annual income increased by approximately 300,000 Yuan in this period. Thirdly, in together approaching the dream of becoming rich, peasants in Xiaoguan village found themselves increasingly united. As there are more villagers coming back to the village from other locations, a strong sense of mutual aid, solidarity and common prosperity has emerged among the peasants. The trust of villagers in the village committee and cadres was also strengthened. In this process, the village committee of Xiaoguan managed to enhance its credibility and prestige, which contributes positively to the management and governance of the village in the future.

The success of Xiaoguan's survival lies in the strong leadership of its village committee, which initiated a common sense and ambitious attempt to rid their village of poverty and become rich (Fig. 2). This created a belief among all the villagers that through collective action and strength, they could revitalise Xiaoguan and combat the decline induced by depopulation. In this process, decisions were made by widely incorporating stakeholders' interests. Many meetings were held to discuss what to do and how to do it. Peasants' views and opinions were heard and respected, while constructive and practicable suggestions were adopted. Thus, motivated by the lure of common prosperity, peasants in Xiaoguan village took the village cadres' suggestions regarding development strategies and worked jointly in new initiatives for economic growth. ${ }^{5}$ The result is satisfying: rural revitalisation is evident and both the rural collective and each household benefit from this development.

\subsection{Rural revival through local social capital: experiences from Åre, Sweden 6}

Rural Sweden experienced a decline from 1945 onwards (although this decline was also seen in many regions before the Second World War too). Whilst the 1970s seemed, as a result of a strong expansion in the public sector at the local level, to mark a slowing of this decline, since the emergence of the knowledge economy in the 1980s, rural decline resumed in most parts of Sweden. There are, however, exceptions to this rule: rural areas in close proximity to the bigger and expanding cities have increased their populations and become integrated into those urban areas, and there also exist a number of remote rural areas that have been able to "swim against the tide" and even increase their population. The mountain village of Åre in Jämtland County is an example of one such successful rural revival in Sweden.

Åre is both a settlement and one of Scandinavia's leading ski resorts. The town is situated within the municipality of Åre, which has a total population of 10,400 inhabitants, of which about 1400 inhabitants live in the settlement itself (Fig. 3). Tourism accounts for $25 \%$ of the municipality's economy, most notably through the downhill skiing and biking resorts in Åre and Storlien. The growth in tourism has resulted in the development of hotels, recreational and shopping opportunities in the area.

Rural decline in Sweden had caused an increasing use of "voice" in rural areas and as a result regional policies have been introduced in order to tackle the depopulation of rural areas in northern

\footnotetext{
5 In China, the village committee and the cadres are elected by all village members following a "one person, one vote" system. Thus, the committee and the cadres represent the interests of all the villagers.

6 This section is partly based on Nordin and Westlund (2009). Interviews and analysis of local newspaper articles on Åre for that article were performed by Sara Nordin at the Mid-Sweden University.
} 


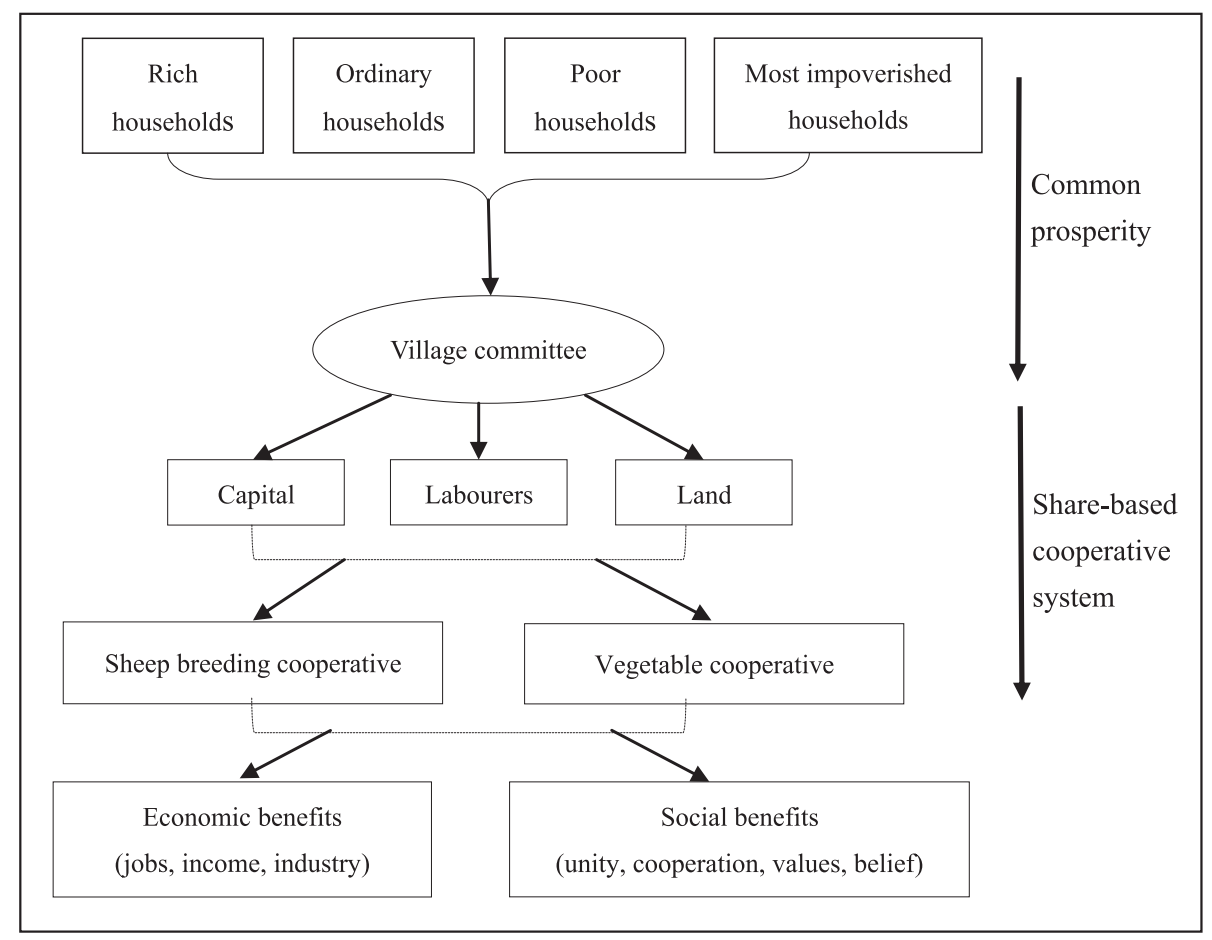

Fig. 2. Mechanism of Xiaoguan's revival model.

Sweden. The first of these policies was adopted in 1965. Whilst at first policies focused solely on the manufacturing industry, in the 1970s the scope of political action was expanded in order to take into account parts of the service sector. Political "voice" became the starting point for large, national government-funded investments in a cableway, ski lifts and hotels in Åre. The investments in this period would likely never have been made without state funding and support, and this triggered a phase of growth.

The 1980s was a period of expansion for Åre, wherein many new external private actors invested in the town. It was also a time when local government in Åre began to play an increasingly important role in promoting local entrepreneurship. In this way, local government became a strong voice for long-term growth by developing the tourism industry. The recession of the early 1990s meant that many of the external "fortune-hunters" went bankrupt, and in response local private firms, with support from local government, took the initiative to form a joint strategy for the destination, a platform for shared values and attitudes towards its guests. A growing view that cooperation was the only way to regain the previous growth emerged. This created much joint (local) social capital in Åre. The work of the community focused on developing a "destination-embracing strategy," creating a sense of joint responsibility for the destination as well as increasing communication and dialogue-values and norms that had not been frequently discussed previously (Nordin and Westlund, 2009). When the successful years of the 1980s were replaced by the hard times spawned by the recession, the destination of Åre had a common platform to lean on, and the population continued to grow, in contrast to most other depopulating mountainous places in Sweden (Fig. 4).

The latter part of the 1990s and the first years of the 2000s marked the appearance of new external "voices". In contrast to the 1980s, these new actors were bigger, and had their own commercial company cultures and external professional business networks. Initially, the new actors almost solely focused on their own businesses and cared little about the rest of the village. This created

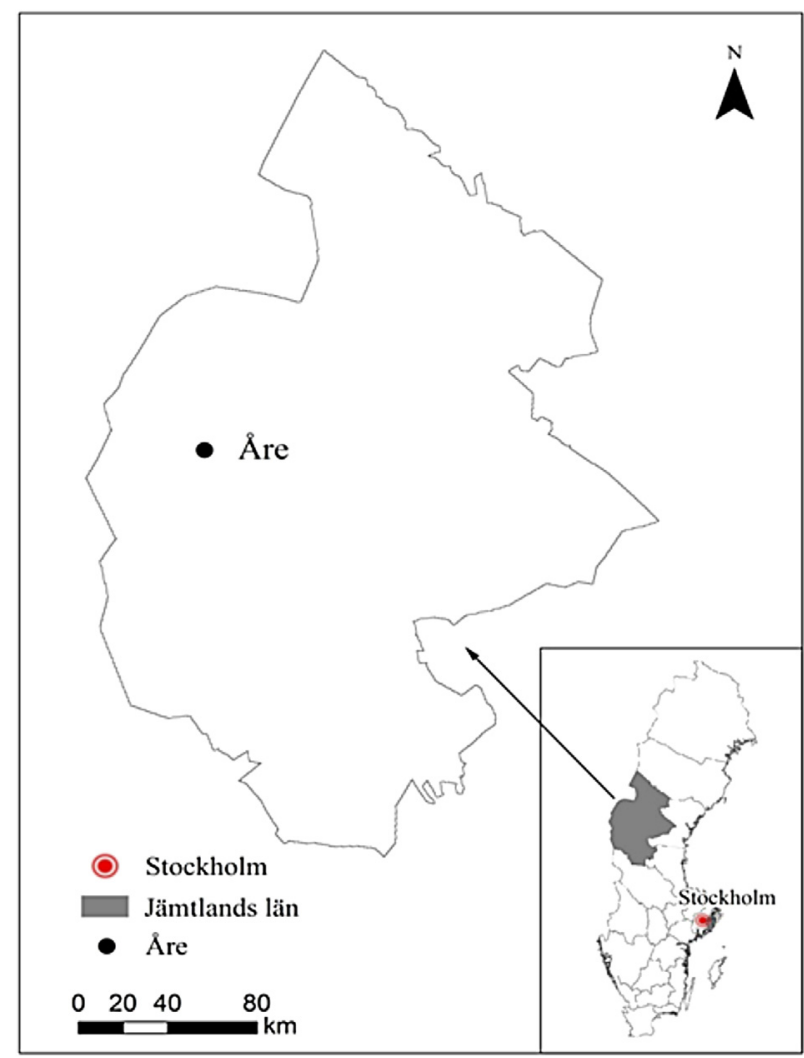

Fig. 3. Åre in Jämtland county, Sweden.

value conflicts with those actors who in the period following the recession had developed a joint strategy for handling common interests. The presence of these new major actors also produced a sense of fear and powerlessness among some of the smaller 
companies.

Simultaneously, the entrance of new actors in the first years of the 2000s marked a strong rejuvenation of Åre. The resort town began reaching out to new customers and markets. More familyoriented and internationally focused, the destination worked hard to extend its tourist season and came up with a new destination governance solution based on public-private cooperation. Tourism has to a greater extent turned into a "real" industry there. However, there are also potential problems with dominating external owners. The "voice" of external stakeholders has increased even further. It is now no longer self-evident that profits will be reinvested in Åre, but redistributed to shareholders and other destinations.

Generally, the great ski interest is a uniting factor in Åre-this was true in the 1970s and is still true today. This is a value that has deep roots in the village, but that also has managed to survive, and it is probably fair to describe it as a value shared by a majority of the population. The volunteer work around big ski competitions has played a significant role in the development of the destination and in keeping the villagers together. Hence the local ski association can be described as a central "voice", but one that has lost influence as the growth has continued. A tight, informal network of local people also has its origins in this local ski association. The members of the association and this network are strongly embedded in the village, they share a sincere interest in skiing and they have also had an interest in the way Åre has developed. Using their influence and their connections, this existing network has attempted to affect the development of their town, even trying to force some newer actors who they have described as "insincere" to shut up shop. The network acts as a symbol of Åre's social capital.

Åre's social capital has developed and transformed during the locality's growth from a village to an international ski resort. From a voice and exit perspective, Åre has showed much more voice than most comparable villages and rural areas in Sweden, but Åre has also been able to attract new and stronger voices in the form of international tourism companies. The case of Åre demonstrates the importance of possessing "multi-level voices": local villagers and small entrepreneurs; political actors at local, regional and even national level; and international companies. Another lesson from Åre lies in the ability of the various actors and stakeholders to adapt to each other and realize their common interests in developing the ski resort by speaking with a common voice towards both customers and the regional and national governments. Thus, the success of Åre is not the result of a single factor or actor, but instead a result of a continuous interplay between actors at different levels and sectors, and diverse combinations of their resources.

While the renewal of Åre has primarily been a commercial success, its social achievements should also be recognised. In the peak season, Åre village can be described as a miniature version of the city centre of the country's capital, Stockholm: this vibrancy makes Åre one of the few rural spots able to attract young people with the lure of an urban lifestyle.

Åre's development into an international ski resort has not, however, been to the benefit of everyone, and not every stakeholder's voice has been able to influence the trajectory taken. Among the older generation of ski tourists, criticism had been raised against the increased commercialisation of the village. The group that is affected to the greatest extent by the growing mountain tourism is the indigenous Sami population and their reindeer husbandry. Snowmobile driving and skiing in the spring can scatter reindeer herds and even worse disturb the reindeer calving so that reindeer cows leave their new-born calves. All stakeholders, as such, have not had the access, standing and influence that Senecah (2004) describes as essential to rural renewal.

\section{Discussion and conclusion}

The two case studies presented here allow similar findings to be drawn in terms of the role played by bottom-up initiatives in revitalizing declining rural areas, in spite of the huge socioeconomic and political differences between China and Sweden. The success of Xiaoguan village and of Åre lies in the local stakeholders' strong "voices" and desire to "become rich", to create new employment opportunities and to conquer conditions of economic recession. These ambitions, the case studies suggest, act as a form of glue, a social capital able to hold people and groups together through their desire to working jointly and in line with similar values and attitudes-even if, as in the case of Åre, not every stakeholder was included in those who had "voice". Development almost always takes place at the expense of some groups' interests and the exclusion of indigenous voices must therefore be denounced as a clear ethical failure in the case of Åre.

Local social capital can serve as a platform for collaboration and interplay with different external actors and sectors. In this process, the endogenous development capability of communities is strengthened and local social capital enhanced when increased unity, cooperation and trust is developed.

Can bottom-up initiatives like those discussed in this paper succeed in revitalizing any depopulating rural area? The answer is mixed: yes, in certain cases, they can, but it is difficult to achieve revitalisation everywhere in the same manner. The case of Xiaoguan village shows that a strong leadership that motivates and leads the local peasants might be decisive. The village committee and the cadres, who both possessed a high level of prestige, acted as

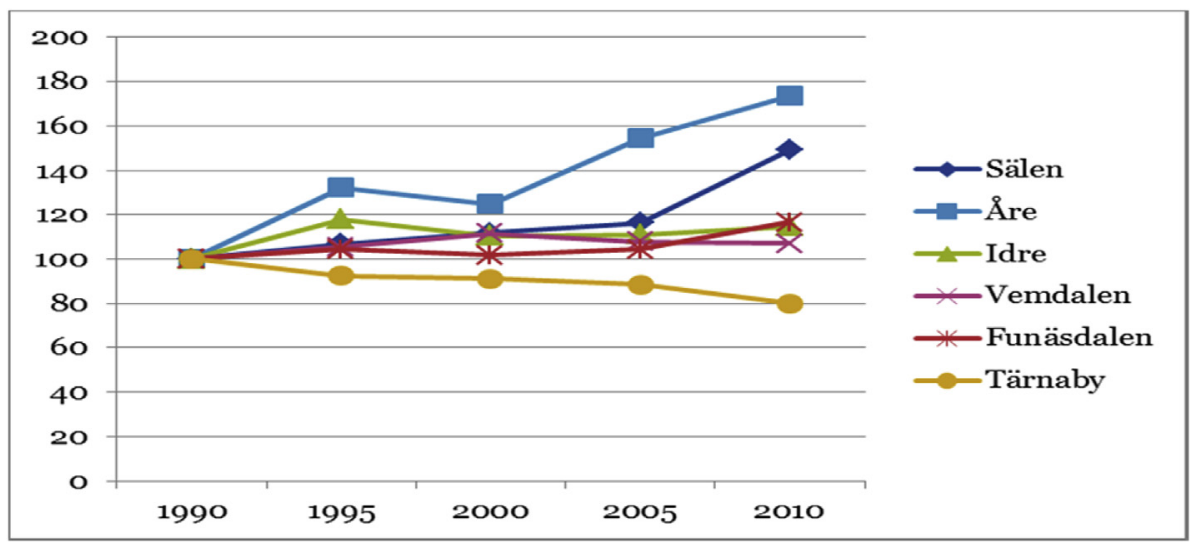

Fig. 4. Population change in major Swedish mountain destinations 1990-2010. Index:1990 = 100. Source: Statistics Sweden. 
the driving force in generating the initiatives and facilitating the process. The Åre case speaks to the way in which even a consciousness of the crisis can act as the key to soliciting collaboration for the joint development of a place. This is essentially what took place in Åre when the recession forced inhabitants and local businesses to choose to either exit or to exercise voice and action. This awareness and common sense made actors in the private, public and tertiary sector work together against the challenges they mutually faced, and to shift from a predominantly competitive attitude to one based more on values of local cooperation. In both cases, strong leadership either by a local committee, local government or leading stakeholders played an important role in aggregating the resources and strength required to achieve a rural revival.

We must not neglect the importance of the roles played by national and regional governments in working with communities to ensure that they adopt a strategic approach to economic development, and in providing regional communities with some of the tools to overcome the considerable challenges they face. The two cases discussed here demonstrate that revitalisation efforts succeed when bottom-up initiatives align with governmental regional development plans and policies, and the internal initiatives of local stakeholders work in combination with the external assistance and support that can be provided by government. These findings highlight the importance of integrating local stakeholders' "voices" into national social and economic development plans, which constitutes a key task for government. Governments can also help rural communities in restructuring and redefining themselves by working to improve economic efficiencies and public services while building strong local identities.

Many small villages and towns in China, Sweden and the rest of the developed and developing world face enormous challenges as we move deeper into the twenty-first century. We can expect a greater number of schools, local industries and stores to be closed, more land abandoned, more facilities left unused and more communities to wither and die, if depopulation continues apace. As we emphasized in the opening of this paper, such a result not only heralds the onset of deep social and cultural problems, as well as signalling the underutilisation of resources, but might also in the case of China lead to problems in food security at a global level. Given that these are the stakes, it is clearly necessary to pursue revitalisation in the face of rural decline. In conversations on the importance of bottom-up initiatives in revitalising communities' development capacities, a tendency exists to discuss industrial development and the creation of jobs; however, as the cases discussed in this paper suggest, the creation of desirable rural lifestyles is equally important. Whilst young people may leave their home villages as a result of shortages of jobs, it is also true that they are attracted by the lure of urban life (its facilities, services and the social amenities) - as such, both economic and social development is to be encouraged simultaneously in the pursuit of a rural revival.

We have provided two examples of rural settlements that in very different contexts seemed to swim against the tide of decline by actively renewing their economies. In spite of the enormous differences between a poor Chinese village and a peripheral but wealthy tourism destination in Northern Europe, we located a series of common traits in their respective success. Through these case studies, we were able to show how actions based on local conditions and context, cooperation, joint goals, and strong leadership, it was possible for the two villages to unite, to raise their voices and to attract external support from business and from government.

The relative importance of endogenous voices, resources and factors in rural revitalization constitutes a fruitful subject for future research. The way in which some voices are not heard or are silenced is also stressed as constituting an important problem for future work in this field.

\section{Acknowledgement}

This work was supported by the National Natural Science Foundation of China under Grant 41130748 and 41301190.

This work was also supported by the Third Party Appraisal of China's Targeted Poverty Alleviation in 2015 and 2016 (Y66L0000AJ). The appraisal was carried out by the Institute of Geographical Sciences and Natural Resources Research, Chinese Academy of Sciences.

The authors appreciate the valuable comments of the referees and the editor.

\section{References}

Beale, C.L., 1975. "The Revival of Population Growth in Non-metropolitan America" Economic Research Service. publication 605. US Department of Agriculture, Washington, DC.

Berry, B.J.L., 1976. The counterurbanization process: urban America since 1970. In: Berry, B.J.L. (Ed.), Urban Affairs Annual Review, vol. 11. Sage, Beverly Hills, CA, pp. 17-30.

Bjorna, H., Aarsaether, N., 2009. Combating depopulation in the northern periphery: local leadership strategies in two Norwegian municipalities. Local Gov. Stud. 35 (2), 213-233.

Bontje, M., 2004. Facing the challenge of shrinking cities in East Germany: the case of Leipzig. Geo J. 61, 13-21.

Borgegård, L.-E., Håkansson, J., Malmberg, G., 1995. Population redistribution in Sweden - long term trends and contemporary tendencies. Geogr. Ann. 77B, $31-45$.

Bowler, I.R., Bryant, C.R., Nellis, M.D., 1992. Contemporary Rural Systems in Transition, vol. 1 and 2. CAB International, Wallingford.

Carr, P.J., Kefalas, M.J., 2009. Hollowing Out the Middle: the Rural Brain Drain and What it Means for America. Beacon Press, Boston.

Champion, A.G., 1988. The reversal of the migration turnaround: resumption of traditional trends. Int. Reg. Sci. Rev. 11 (3), 253-260.

Cullingworth, J.B., Nadin, V., 2002. Town and Country Planning in the UK, thirteenth ed. Routledge, London.

Elshof, H., Bailey, A., 2015. The role of responses to experiences of rural population decline in the social capital of families. J. Rural Community Dev. 10 (1), 72-93.

Freeman, C., Cheyne, C., 2008. Coasts for sale: gentrification in New Zealand. Plan. Theory Pract. 9 (1), 33-56.

Friedmann, J., 1966. Regional Development Policy - A Case Study of Venezuela, MA. MIT Press, Cambridge.

Gibson, C., Dufty, R., Drozdzewski, D., 2005. Resident attitudes to farmland protection measures in the northern rivers region, New South Wales. Aust. Geogr. 36 (3), 369-383.

Hassebrook, C., 2003. Strategies to Revitalize Rural America, a Compilation of Articles from the Center for Rural Affairs Newsletter, pp. 1-22.

Hirschman, A.O., 1970. Exit, Voice, and Loyalty: Responses to Decline in Firms, Organizations, and States. Harvard University Press, Cambridge.

Johnson, K.M., Beale, C.L., 1998. The Rural Rebound. The Wilson Quarterly, pp. $16-27$.

Krugman, P., 1991. Increasing returns and economic geography. J. Political Econ. 99 483-499.

Li, Y.H., 2011. Urban-rural interaction in China: historic scenario and assessment. China Agric. Econ. Rev. 3 (3), 335-349.

Li, Y.H., 2012. Urban-rural interaction patterns and dynamic land use: implications for urban-rural integration in China. Reg. Environ. Change 12 (4), 803-812.

Li, Y.H., Hu, Z.C., 2015. Approaching integrated urban-rural development in China: the changing institutional roles. Sustainability 7, 7031-7048.

Li, Y.H., Zhang, Q., 2013. Human-environment interaction in China: evidence of land-use change in Beijing-Tianjin-Hebei metropolitan region. Hum. Ecol. Rev. 20 (1), 26-35.

Li, Y.H., Westlund, H., Cars, G., 2010. Future urban-rural relationship in China: comparison in a global context. China Agric. Econ. Rev. 2 (4), 396-411.

Liu, Y.S., Liu, Y., Chen, Y.F., Long, H.L., 2010. The process and driving forces of rural hollowing in China under rapid urbanization. J. Geogr. Sci. 20 (6), 876-888.

Long, H.L., Zou, J., Pykett, J., Li, Y.R., 2011. Analysis of rural transformation development in China since the turn of the new millennium. Appl. Geogr. 31, 1094-1105.

Long, H.L., Li, Y.R., Liu, Y.S., Woods, M., Zou, J., 2012. Accelerated restructuring in rural China fueled by 'increasing vs. decreasing balance' land-use policy for dealing with hollowed villages. Land Use Policy 29 (1), 11-22.

Marsden, T., Sonnino, R., 2008. Rural development and the regional state: denying multifunctional agriculture in the UK. J. Rural Stud. 24 (4), 422-431.

Myrdal, G., 1957. Economic Theory and Underdeveloped Regions. Duckworth, London.

Naples, N., 2000. Economic Restructuring and Racialization: Incorporating of 
Mexicans and Mexican-americans in the Rural Midwest. Working Paper No. 7 (April). The Center for Comparative Immigration Studies, University of California San Diego.

Natsuda, K., Igusa, K., Wiboonpongse, A., Thoburn, J., 2012. One village one productrural development strategy in Asia: the case of OTOP in Thailand. Can. J. Dev. Stud. 33 (3), 369-385.

Nelson, P.B., 2005. Migration and the spatial redistribution of nonearnings income in the United States: metropolitan and nonmetropolitan perspectives from 1975 to 2000. Environ. Plan. A 37, 1613-1636.

Nelson, L., 2007. Farmworker housing and spaces of belonging in Woodburn, Oregon. Geogr. Rev. 97 (4), 520-541.

Nelson, L., Nelson, P.B., 2010. The global rural: gentrification and linked migration in the rural USA. Prog. Hum. Geogr. 1-19.

Nelson, P.B., Oberg, A., Nelson, L., 2010. Rural gentrification and linked migration in the United States. J. Rural Stud. 26, 343-352.

Nordin, S., Westlund, H., 2009. Social capital and the life cycle model: the transformation of the destination of Åre. Tour. Int. J. 57 (3), 259-284.

Phillips, M., Page, S., Saratsi, E., Tansey, K., Moore, K., 2008. Diversity, scale, and green landscapes in the gentrification process: traversing ecological and socia science perspectives. Appl. Geogr. 28, 54-76.

Schilling, J., Logan, J., 2008. Greening the rust belt: a green infrastructure model for right sizing America's shrinking cities. J. Am. Plan. Assoc. 74 (4), 451-466.

Senecah, S., 2004. The trinity of voice: the role of practical theory in planning and evaluating the effectiveness of environmental participatory processes. In : Depoe, Stephen P., Delicath, John W., Elsenbeer, Marie-France Aepli (Eds.) Communication and Public Participation in Environmental Decision Making. State University of New York Press, Albany, pp. 13-33.

Solana-Solana, M., 2010. Rural gentrification in Catalonia, Spain: a case study of migration, social change and conflicts in the Empordanet area. Geoforum 41, 508-517.

Spencer, D., 1997. Counterurbanisation and rural depopulation revisited: landowners, planners and the rural development process. J. Rural Stud. 13 (1), 75-92.

Stockdale, A., 2010. The diverse geographies of rural gentrification in Scotland. J. Rural Stud. 26, 31-40.

Stockdale, A., Findlay, A., Short, D., 2000. The repopulation of rural Scotland: opportunity and threat. J. Rural Stud. 16 (2), 243-257.

Su, S.L., Jiang, Z.L., Zhang, Q., Zhang, Y., 2011. Transformation of agricultural landscapes under rapid urbanization: a threat to sustainability in Hang-Jia-Hu region, China. Appl. Geogr. 31, 439-449.

Sun, H., Liu, Y.S., Xu, K.S., 2011. Hollow villages and rural restructuring in major rural regions of China. Chin. Geogr. Sci. 21 (3), 354363.

Torres, R.M., Popke, J.E., Hapke, H.M., 2006. The South's silent bargain: rural restructuring, Latino labor and the ambiguities of migrant experience. In: Smith, H.A., Furuseth, O.J. (Eds.), Latinos in the New South: Transformations of Place. Ashgate, Burlington, VT, pp. 37-67.

van der Ploeg. J.D., Renting, H., Brunori, G., Knickel, K., Mannion, J., Marsden, T., de Roest, K., Sevilla Guzmán, E., Ventura, F., 2000. Rural development: from practice and policies to theory. Sociol. Rural. 40, 391-408.

Venables, A.J., 1996. Equilibrium locations of vertically linked industries. Int. Econ. Rev. 37, 341-359.

Vias, A., Nelson, P., 2006. Changing rural livelihoods. In: Kandel, W., Brown, D. (Eds.), The Population of Rural America: Demographic Research for a New Century. Kluwer, New York, pp. 75-102.

Westlund, H., 2002. An unplanned green wave: settlement patterns in Sweden during the 1990s. Environ. Plan. A 34 (2002), 1395-1410.

Westlund, H., 2014. Urban futures in planning, policy and regional science: are we entering a post-urban world? Built Environ. 40 (4), 447-457.

Wood, R.E., 2008. Survival of Rural America: Small Victories and Bitter Harvests. University Press of Kansas, Kansas.

Zhou, Y.X., Ma, L.J.C., 2000. Economic restructuring and suburbanization in China. Urban Geogr. 21 (3), 205-236. 